\title{
Clinical, pathological and molecular genetic findings in small intestinal follicle centre cell lymphoma
}

\author{
Hugh J Freeman mD, MiChelle E ANDERson, RANDy D Gascoyne MD
}

HJ Frgeman, ME ANDERSON, RD GASCOYNE. Clinical, pathological and molecular genetic findings in small intestinal follicle centre cell lymphoma. Can J Gastroenterol 1997;11(1):31-34. A 44-year-old male was evaluated for an iron deficiency anemia. Endoscopic investigation revealed marked serpiginous ulceration of the proximal small intestine due to a B cell lymphoma. Endoscopic small intestinal mucosal biopsies revealed a nodular lym. phoid infiltrate, and polymerase chain reaction of biopsy material from the same site demonstrated rearrangement of the $b c l-2$ gene, the molecular equivalent of the $t(14 ; 18)$ chromosomal translocation. Primary small bowel follicular small cleaved cell lymphoma was diagnosed. Endoscopic tissue biopsies for immunophenotyping, molecular genetic studies or both are a valuable diagnostic aid for precise classification of lymphoid neoplasms in the gastrointestinal tract.

Key Words: Apoptosis, B cells, bcl-2 gene rearrangement, BCL-2 protein expression, Duodenal ulceration, Follicle cell lymphoma, Follicular lymphoma, Iron deficiency anemia, Lymphoma
Observations génétiques, cliniques, pathologiques et moléculaires dans le lymphome B du grêle

RÉSUMÉ : Un homme de 44 ans a été examiné pour anémie ferriprive. L'examen endoscopique a révélé la présence d'ulcérations serpigineuses marquées au niveau de l'intestin grêle proximal à cause de la présence d'un lymphome B. Les biopsies des muqueuses du grêle réalisées à l'endoscopie ont révélé la présence d'infiltrats lymphoîdes nodulaires et l'amplification génique du matériel de la biopsie provenant du même site a démontré un réarrangement du gène bcl-2, équivalent moléculaire de la translocation du chromosome T (14:18). Un diagnostic de lymphome primitif du grêle à cellules folliculeuses clivées a été posé. Les biopsies des tissus prélevés à l'endoscopie pour immuno-phénotypage, examen génétique moléculaire ou les deux, sont des outils diagnostiques utiles pour la classification précise des neoplasies lymphoïdes du tractus gastro-intestinal.
$\mathrm{L}$ ymphoma may involve any site within the gastrointestinal tract and may be focal, multifocal or diffuse. Diagnosis is sometimes difficult, and classification is complicated by schema based largely on lymphomatous involvement of lymph nodes. In 1982, a proposed working formulation based purely on morphological findings was published (1). It closely paralleled the Rappaport classification because it was modified before $1982(2,3)$ and it appeared to be clinically useful since it seemed to predict survival and curability. It was not clear, however, whether this classification applied to localized gastrointestinal disease.
Over the next decade, development of increasing numbers of monoclonal antibodies and molecular genetic markers permitted subdivision of lymphoid cells and their tumours into various subtypes, levels of differentiation and proliferation characteristics. Diagnosis of mucosa-associated lymphoid tissue (MALT) lymphomas, including even those with a nodular appearance, for example, were made more precise because MALT lymphomas do not demonstrate $b c l-2$ or bcl-1 gene rearrangements (4). As a result, another group (4) proposed a new classification and nomenclature to separate the different types of lymphoid neoplasms more

Department of Medicine (Gastroenterology), University of British Columbia, Vancouver, British Columbia

Correspondence and reprints: Dr Hugh Freeman, ACU F-137, Gastroenterology, Vancouver Hospital (UBC Site), 2211 Wesbrook Mall, Vancouver, British Columbia V6T IW5. Telephone 604-822-7216, fax 604-822-7236

Received for publication November 28, 1995. Accepted February 5, 1996 


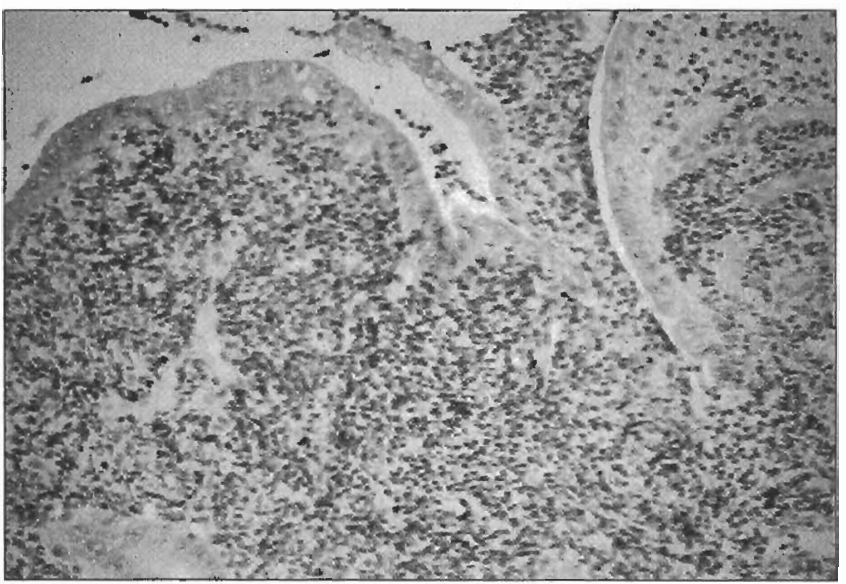

Figure 1) Small intestinal Lymphoma with intact epithelium. Immunoperoxidase labelling studies with B cell markers were positive (hematoxylin and $\operatorname{cosin} \times 55$ )

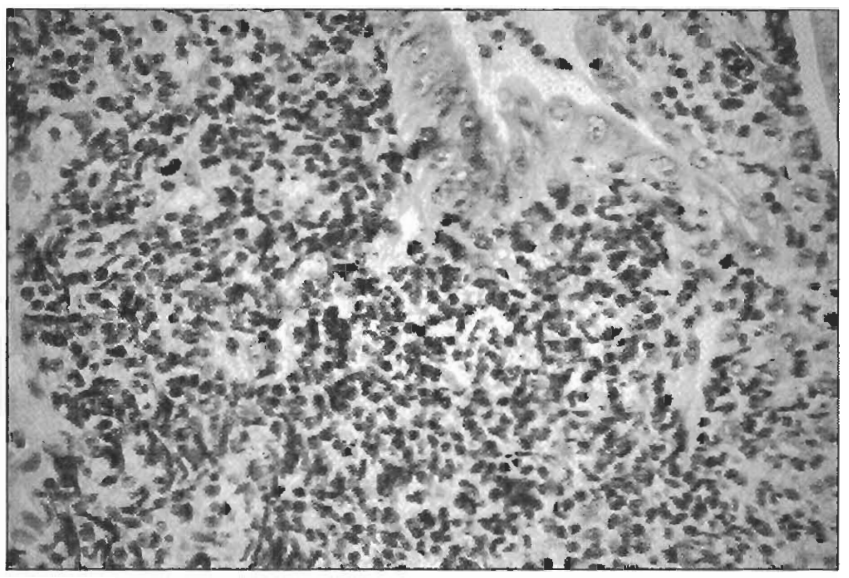

Figure 2) Higher power view of same field shown in Figure I (hematoxylin and eosin $x ! 10$ )

accurately and facilitate classification of extranodal lymphomas.

A localized lymphoma of the small bowel detected in a man with iron deficiency anemia is presented in this report. Biopsies of the proximal duodenum revealed a small $B$ cell lymphoma, and additional studies, including polymerase chain reaction (PCR) of fresh small intestinal biopsies, permitted a specific diagnosis of a follicular lymphoma, a B cell lymphoma that usually predominates in lymph nodes and spleen. Detection of the $b c l-2$ gene rearrangement - the molecular equivalent of the $t(14 ; 18)$ chromosomal abnormality - together with histological and immunophenotypic data, permitted a precise classification for clinical management.

\section{CASE PRESENTATION}

A 44-year-old male was referred for evaluation of anemia and iron deficiency. He was followed and investigated in his community hospital for 14 months after initial presentation, at which time his hemoglobin was $46 \mathrm{~g} / \mathrm{L}$. Physical examinations over the course of his evaluations were normal. Fecal occult blood tests (total of 12) were negative, as were inves-

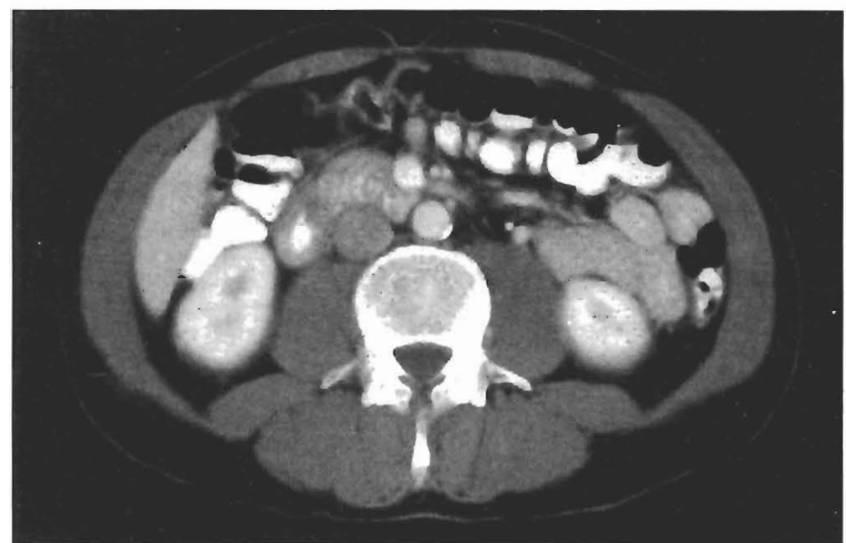

Figure 3) Computerized tomographic scan with oral contrast showing thickened duodenal wall; there was no nodal enlargement

tigations to exclude a hematological cause for anemia, such as studies to exclude hemolysis. Despite negative fecal occult blood tests studies were also done to exclude a gastrointestinal cause for blood loss. These included repeated barium radiological and fibreoptic endoscopic studies of the upper and lower gastrointestinal tracts. Nuclear medicine imaging studies were also performed, including a tagged red blood cell scan and a Meckel's scan. All investigations were normal, including a rectal biopsy; however, biopsies of the upper gastrointestinal tract were not done. Repeated hospitalizations were required and transfusions were administered from March 1994 until May 1995. He was referred for further evaluation due to persistent anemia.

Because a proximal small intestinal mucosal disorder, eg, occult celiac disease, can present as iron deficiency anemia, an upper endoscopic examination was repeated. This revealed an abnormal proximal duodenum. The mucosal surface was erythematous and swollen, with deep linear and serpiginous ulceration that extended from the distal portion of the duodenal bulb to the transverse portion of the distal duodenum. These changes appeared to be reminiscent of those seen in Crohn's disease involving the upper intestinal tract $(5,6)$ and to be typical of changes previously detailed for duodenal lymphoma $(7,8)$. The gastric mucosa appeared normal, and gastric biopsies from the body and antrum showed no evidence of a lymphoproliferative disorder. Routine hematoxylin-eosin and silver stains of these gastric biopsies for detection of Helicobacter pylori were also negative. Multiple biopsies of the duodenum (Figures 1,2) showed features of a lymphoma: follicular small cleaved cell type. Biopsies also demonstrated a nodular architecture composed of a monomorphous infiltrate of small cleaved lymphocytes. The cells were small with irregular nuclei, ind istinct nucleoli and scant cytoplasm. Immunoperoxidase labelling of lymphoid cells was positive for the B cell antigen marker L-26 (CD-20). Kappa and lambda stains failed to disclose light chain restriction while BCL-2 protein labelling of lymphoid cells was strongly positive.

Further studies were done to aid in the treatment evaluation of this patient. A computerized tomographic scan of 


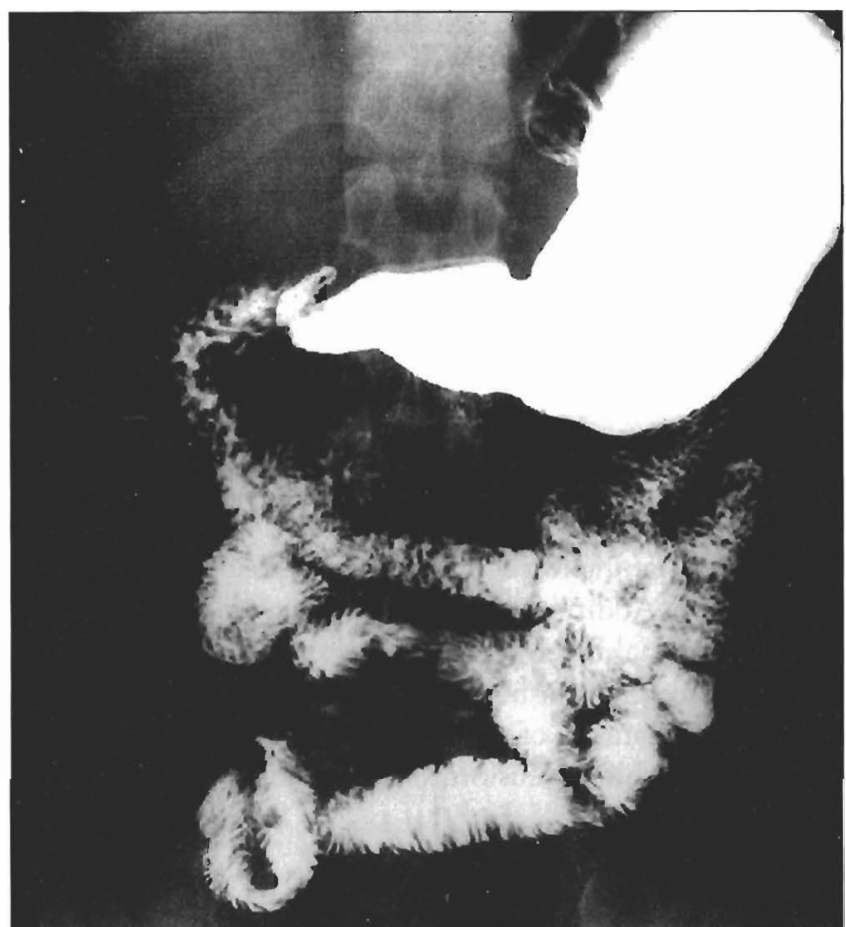

Figure 4) Barium radiological study of the upper gastrointestinal tract revealed thickened duodenal folds; the rest of the small intestine was normal

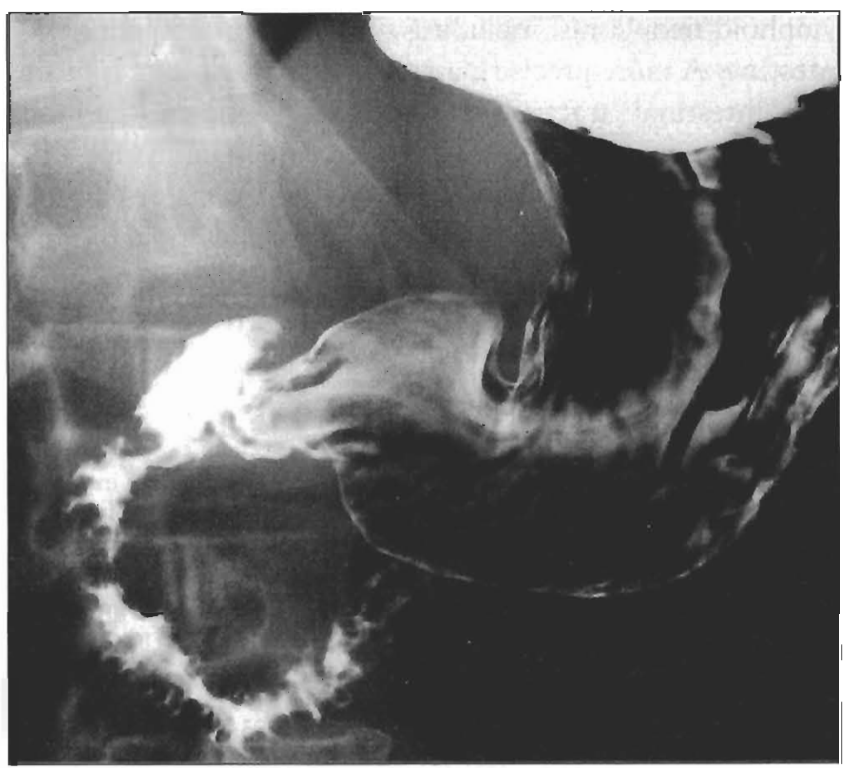

Figure 5) Barium radiological study of the duodenal C loop showing narrowing of the lumen with thickened mucosal folds

the abdomen and pelvis showed uniform thickening of the proximal duodenum but no lymphadenopathy (Figure 3). Another barium radiographic study of the upper gastrointestinal tract revealed mucosal fold thickening in the proximal duodenum, but normal-appearing distal duodenum, jejunum and ileum (Figures 4,5). Other studies, including lymphangiography, bone marrow aspiration and biopsy, as well as quantitative immunoglobulin studies, were normal.

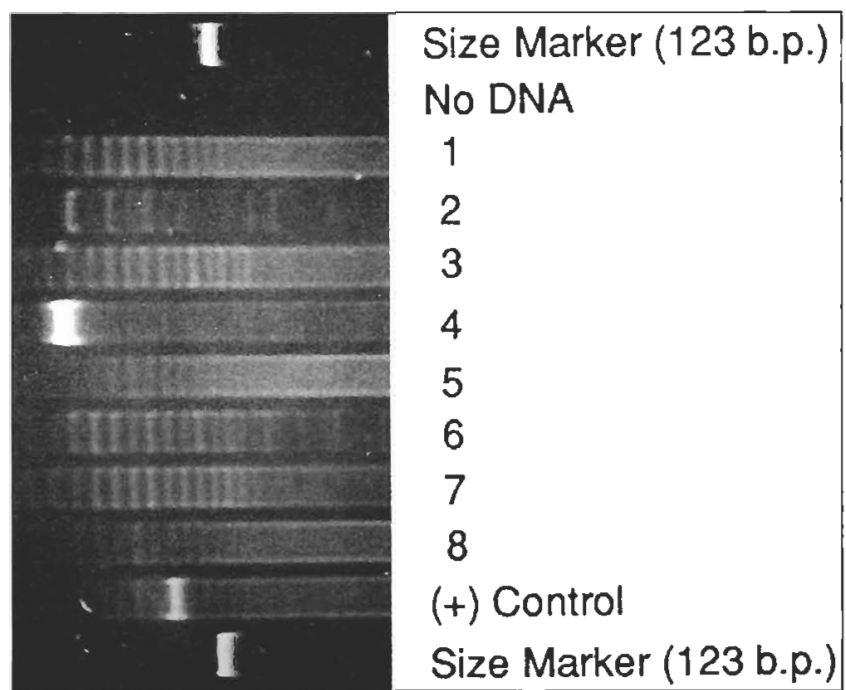

Figure 6) Ethidium bromide-stained 12\% polyacrylamide gel showing monoclonal rearrangement of the immunoglobulin heavy chain gene by polymerase chain reaction (lane 4). A 123 base pair size marker is present on the top and bottom of the gel ("Size Marker 123 b.p."). A "NoDNA" lane serves as a control for contamination. The "(+) Control" lane contains DNA from a B cell leukemia cell line, KM3. Other lanes show the typical polyclonal ladder of benign $B$ cell proliferations

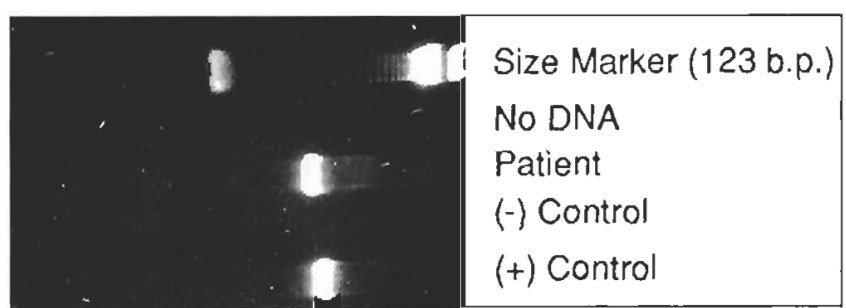

Figure 7) Ethidium bromide-stained 2\% agarose gel showing bcl-2 rearrangement by polymerase chain reaction ("Patient"). Note that there is a slight variation in the size of the band compared with the " $(+)$ Control" lane, which contains DNA from a known follicular lymphoma with t $14 ; 18$ ) and a bcl-2 rearrangement (major breakpoint region), because each bcl-2 rearrangement is unique to the specific tumour. A 123 base pair size marker is present on the top of the gel ("Size Marker 123 b.p."). A "No DNA" lane serves as a control for contamination

During diagnostic evaluation of the lymphoma, duodenal mucosal biopsies were also collected for gene rearrangement studies. B cell clonality was assessed using a consensus primer strategy incorporating $\mathrm{V}$ region and $\mathrm{J}$ region primers for the immunoglobulin heavy chain region (VJ-PCR) (9). Rearrangements of the $b c l-2$ gene were detected by PCR as previously described (10). These studies confirmed a monoclonal B cell population by VJ-PCR (Figure 6), as well as PCR evidence of a $b c l-2$ gene rearrangement at the major break-point region (Figure 7).

\section{DISCUSSION}

Follicular lymphoma is one of the most common human B cell lymphoid neoplasms. Prior studies have demonstrated that the lymphoma cells have a translocation between chromosomes 14 and 18 , juxtaposing the immunoglobulin heavy 
chain gene with the $b c l-2$ proto-oncogene $(11,12)$. Most patients with this type of lymphoma have involvement of lymph nodes, spleen, bone marrow and, occasionally, peripheral blood (4). Our patient had a lymphoid neoplasm localized to the proximal duodenum. Based on immunophenotyping of the small intestinal biopsies, the iymphoma was characterized as a low grade B cell lymphoma with BCL-2 protein expression (4). Using the technique of PCR to classify this lymphoma more specifically, a follicular or follicle centre cell lymphoma with a bcl-2 gene rearrangement was defined (4). This lymphoma is typically composed of cleaved follicle centre cells or centrocytes (11). In up to $90 \%$ of cases $(10,13,14)$ the $t(14 ; 18)$ chromosomal abnormality can be detected at a molecular level with rearrangement of the $b c l-2$ gene $(10,13,14)$.

It is believed that the $b c l-2$ or 'anti-apoptosis' gene is 'switched off' at the translational level in the normal germinal centre cells. Expression of BCL-2 protein permits accumulation of long-lived centrocytes (11-14). In addition, expression of the BCL-2 protein is a useful marker to distinguish reactive follicular hyperplasia (follicles are BCL2-negative) from follicular lymphoma (follicles usually BCL2-positive). Moreover, it has been suggested that when a resting $B$ cell carrying the $b c l-2$ gene translocation undergoes blast transformation in response to antigen, there is a failure to 'switch off' the $b c l-2$ gene, and this genetic alteration may contribute to lymphoma development (4).

Although histology remains the gold standard for diagnosis and classification of lymphoid neoplasms, other studies including immunophenotyping, and cytogenetic and molecular genetic analyses may provide useful information for further subclassification of these disorders. In addition to routine histology, both frozen-section immunophenotyping and molecular genetic studies, particularly PCR, can be performed on endoscopic biopsy specimens (15). These techniques can provide important information about both lineage and clonality, as well as provide specific details useful

\section{REFERENCES}

1. National Cancer Institute sponsored study of classifications of non-Hodgkin's lymphomas. Summary and description of a working formulation for clinical usage. Cancer 1982;49:2112-35.

2. Rappaport H. Tumors of the hematopoietic system. In: Atlas of Tumor Pathology, Series 1, Section 3, Fascicle 8. Washington: US Armed Forces Institute of Pathology, 1966.

3. Nathwani BN. A critical analysis of the classification of non-Hodgkin's lymphoma. Cancer 1979;44:347-84.

4. Harris NL, Jaffe ES, Stein H, et al. A revised European-American classification of lymphoid neoplasms: a proposal from the International Lymphoma Study Group. Blood 1994;84:1361-92.

5. Freeman HJ. Upper gastrointestinal tract Crohn's disease. Can J Gastroenterol 1990;4:26-30.

6. Sukhabote J, Freeman HJ. Granulomatous (Crohn's) disease of the upper gastrointestinal tract. A study of 22 patients with mucosal granulomas. Can J Gastroenterol 1993;7:605-9.

7. Freeman HJ, Endelman AA, Forward AD, Quenville NF. Diffuse multifocal lymphoma of the small intestine presenting as a duodenal ulcer. Can Med Assoc ] 1981;125:599.602

8. Wang HH, Lin JT, Chiu CC, Chiang IP, Wu MS, Wang TH. Endoscopic features of mucosa-associated lymphoid tissue lymphoma of the duodenum. Gastrointest Endosc 1995;41:258-61. for the subclassification of malignant lymphomas. Rapid freezing in liquid nitrogen results in biopsy specimens that can be used for complex immunophenotyping, followed by extraction of DNA for gene rearrangement studies. This approach maximizes the use of small endoscopic biopsies.

Rearrangements of the $b c l-2$ gene characterize most follicular lymphomas, as well as $15 \%$ to $20 \%$ of de novo diffuse large B cell lymphomas (4). Rearrangements of the bcl-1 gene are typically found in mantle cell lymphomas, the histological hallmark of multiple lymphomatous polyposis of the gastrointestinal tract. Neither of these chromosomal translocations is detected in low grade B cell lymphomas of MALT. Therefore this molecular genetic information is helpful in assigning a specific diagnosis once a lymphoma is documented. Additionally, use of molecular techniques to establish a clonal B cell neoplasm helps to distinguish malignant lymphomas from benign infiltrates and has led to the virtual disappearance of the word 'pseudolymphoma', a term of unquestionable confusion for clinicians and pathologists alike.

\section{CONCLUSIONS}

Endoscopic biopsies of the gastrointestinal tract provide sufficient material for routine histology, as well as frozen section material for immunophenotyping and molecular genetic studies. A systematic diagnostic strategy using these techniques will greatly facilitate the specific classification of lymphoid neoplasms, including those localized in the small intestine. A more precise classification of lymphomas in the gastrointestinal tract using modern diagnostic methods should discourage the use of the term pseudolymphoma, improve our understanding of the pathogenesis of lymphomas and reduce the number of repeated endoscopic biopsies and more invasive surgical procedures used to establish a diagnosis. All of these factors should permit the development of optimum treatment regimens for these increasingly recognized extranodal lymphomas.

9. Trainor KJ, Brisco MJ, Story CJ, Morley AA. Monoclonality in B-lymphoproliferative disorders detected at the DNA level. Blood 1990;75:2220-2.

10. Horsman DE, Gascoyne RD, Coupland RW, Coldman AJ, Adomat SA. Comparision of cytogenetic analysis, Southern analysis, and polymerase chain reaction for the detection of $\mathrm{t}(14 ; 18)$ in follicular lymphoma. Am J Clin Pathol 1995;103:472-8.

11. Tsujimoto $\mathrm{Y}$, Cossman J, Jaffe $\mathrm{E}$, Croce $\mathrm{CM}$. Involvement of the $b c \mathrm{c}-2$ gene in human follicular lymphoma. Science 1985;228:1440-3.

12. Ngan BY, Chen-Levy Z, Weiss LM, Warnke RA, Cleary ML. Expression in non-Hodgkin's lymphoma of the bcl-2 protein associated with the $t(14 ; 18)$ chromosomal translocation. N Engl J Med 1988;318:1638-44

13. Hockenbery DM, Zutter M, Hickey W, Nahm M, Korsmeyer S. BCL2 protein is topographically restricted in tissues characterized by apoptotic cell death. Proc Natl Acad Sci USA 1991;88:6961-5.

14. McDonnell TJ, Deane N, Platt FM, et al. Bcl-2 immunoglobulin transgenic mice demonstrate extended $\mathrm{B}$ cell survival and follicular lymphoproliferation. Cell 1989;57:79-88.

15. Sukpanichnant S, Venecak-Jones CL, McCurley TL. Determination of B-cell clonality in paraffin-embedded endoscopic biopsy specimens of abnormal lymphocytic infiltrates and gastrointestinal lymphoma by polymerase chain reaction. Am J Clin Pathol 1994;102:299-305. 


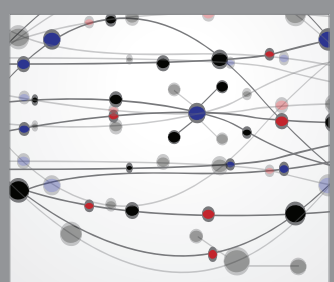

The Scientific World Journal


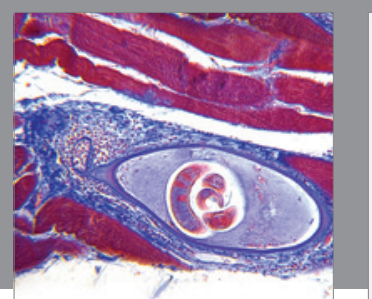

Gastroenterology Research and Practice

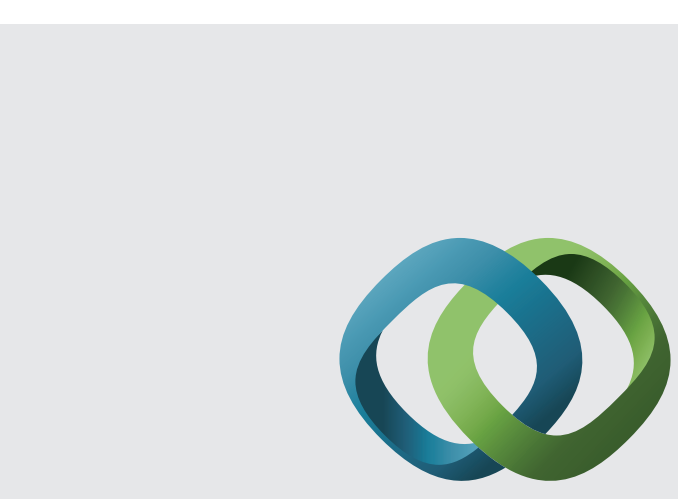

\section{Hindawi}

Submit your manuscripts at

http://www.hindawi.com
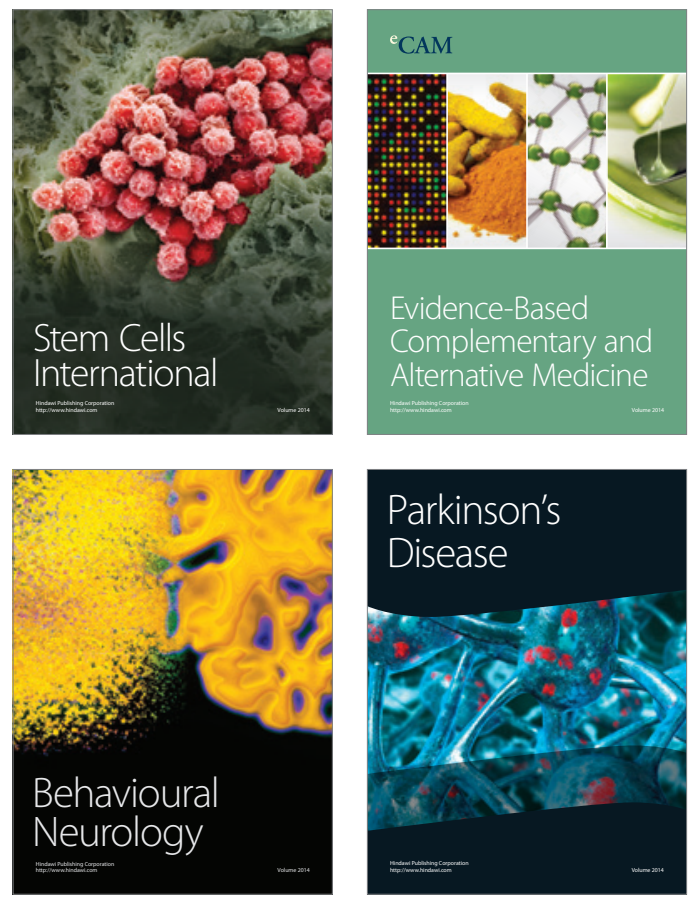
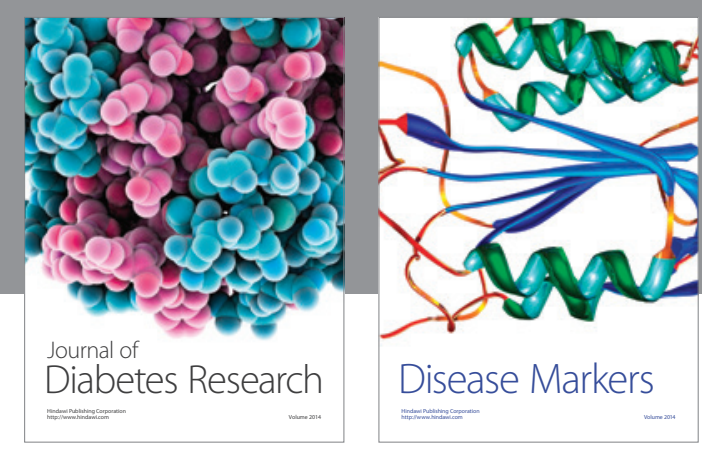

Disease Markers
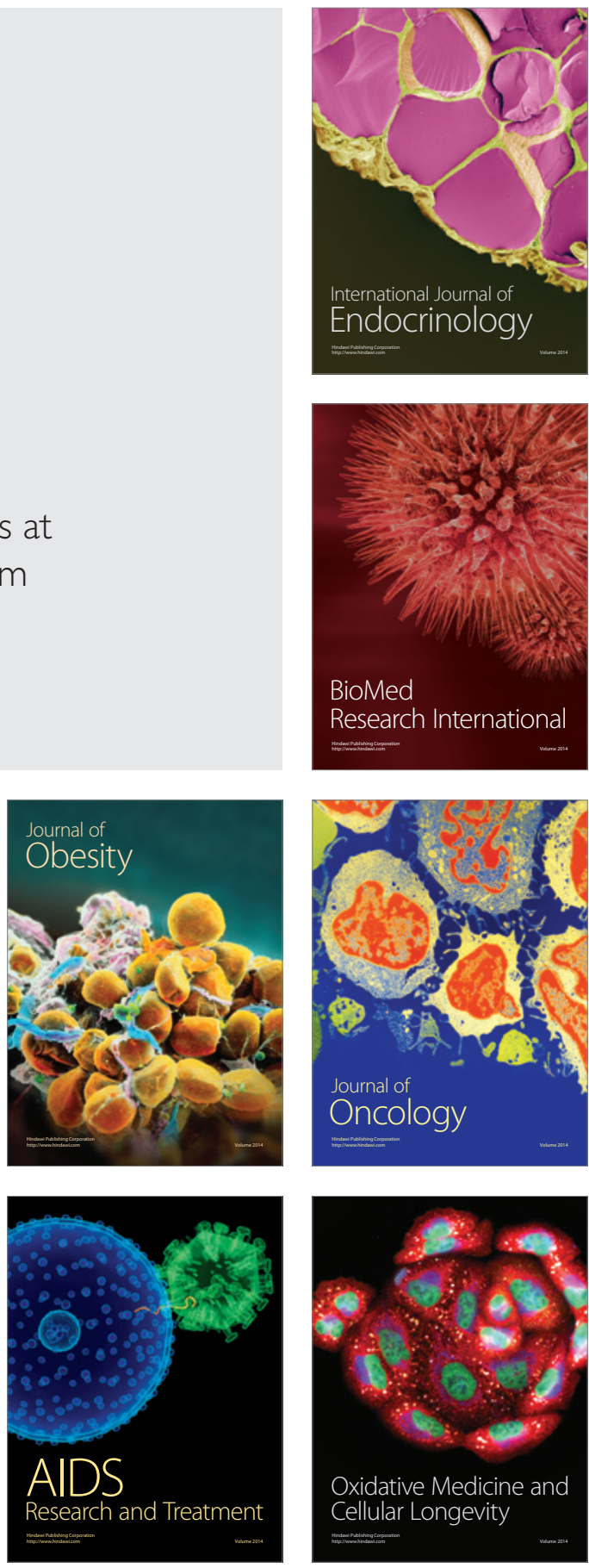